\title{
Economy down, health costs up
}

Published at www.cmaj.ca on Nov. 24

$\mathrm{T}$ he proportion of Canada's gross domestic product (GDP) spent on health care in 2009 will hit an all-time high of $11.9 \%$, up from $10.8 \%$ in 2008 , according to figures released by the Canadian Institute for Health Information (CIHI).

"Taken out of context, these numbers might alarm some. But it's important to remember these sorts of spikes aren't unusual in recessionary times," Graham Scott, chair of the CIHI board, told an Economic Club of Canada event in Ottawa, Ontario. "Peak periods of health spending relative to the economy coincide almost precisely with recessionary periods over the last 30 years. Canadians don't get any less sick as the economy shrinks. In fact, the opposite may very well be true. So while the growth in health spending is much the same as years past, it's eating up a greater share of our GDP."

In total, Canada is expected to spend around $\$ 183.1$ billion on health care in 2009 , an increase of $\$ 9.5$ billion from 2008, says the report National Health Expenditure Trends (secure.cihi.ca/cihiweb /products/National_health_expenditure _trends_1975_to_2009_en.pdf), released on Nov. 19. That is an increase of $\$ 241$ per Canadian, which brings the amount of money spent on health care per Canadian in 2009 to an estimated \$5452.

"The increases we're seeing are not unique. The reality is, they're in line with other developed nations and consume slightly less of our GDP than in France, Germany, Switzerland and Belgium," said Scott. "Now, when it comes to overall health care spending, it will be of no surprise to anyone in this room that the US is the world's undisputed champion. Their total spending on health care per person is nearly twice as high as Canada's. And that's with 45 million Americans uninsured."

The CIHI report also notes that funding for hospitals, at $\$ 51$ billion, accounts for most of the money spent on health care in $2009(27.8 \%)$, followed by

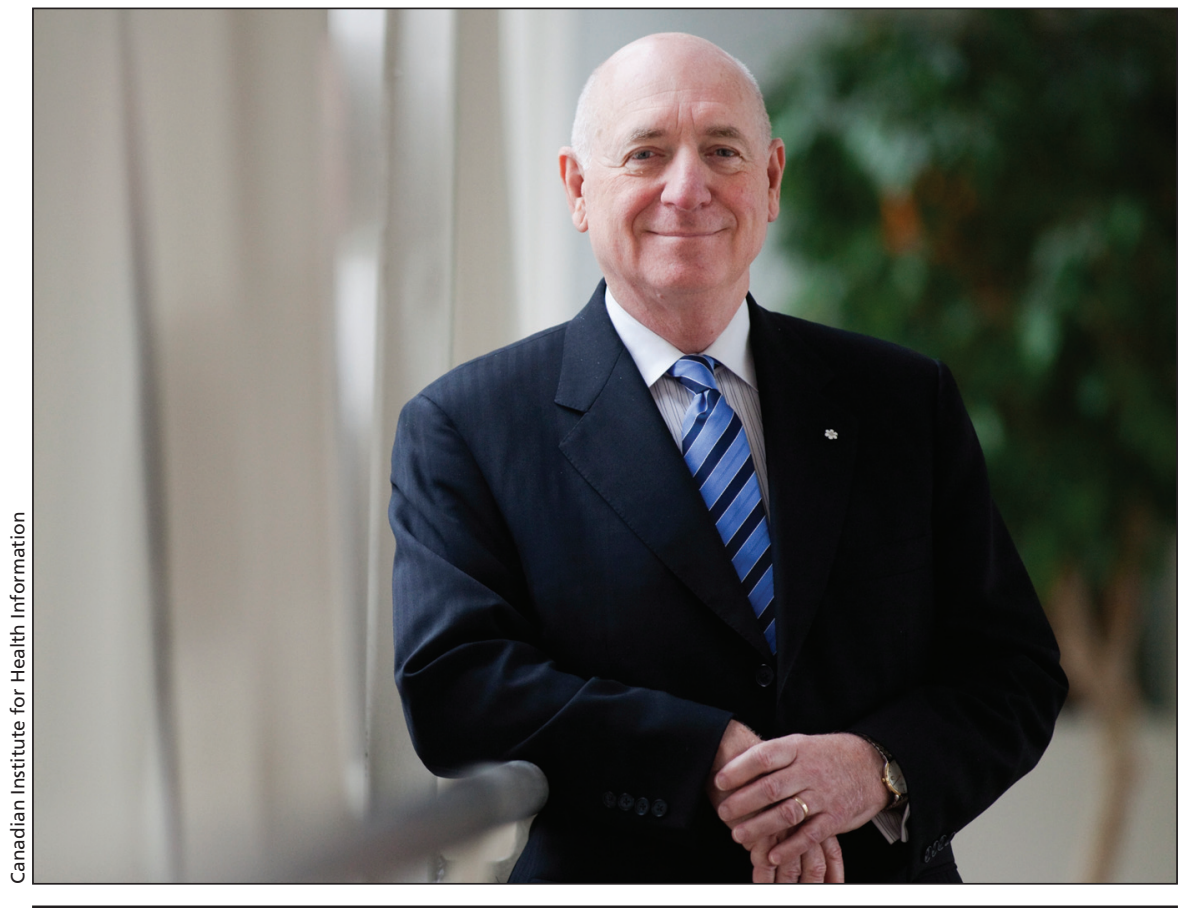

Peak periods of health spending relative to the economy coincide almost precisely with recessionary periods over the last 30 years, says Graham Scott, board chair of the Canadian Institute for Health Information.

spending on drugs, at $\$ 30$ billion $(16.4 \%)$. The percentage of spending on hospitals, however, has declined dramatically over the past 30 years. In 1975 , it accounted for $44.7 \%$ of health care expenditures. The percentage of health care dollars spent on drugs, on the other hand, nearly doubled during the same period. Of the $\$ 183.1$ billion expected to be spent in total in $2009,70 \%$ will come from the public sector.

"That's lower than the OECD [Organisation for Economic Co-operation and Development] average. And it's been that way since 1997," Scott said. "What sets us apart from some of our European counterparts is more private spending here on prescription drugs. That's been the fastest growing component of our health spending over the past two decades."

Another major health care expenditure is for physicians. In 2009, payments to doctors will be an estimated $\$ 25.6$ billion, or $14 \%$ of total spending. According to the report, the expected growth rate for physician spending is $8.8 \%$, higher than the expected rates for hospitals and drugs (each estimated at 5.1\%).

"CIHI's data shows that recently, the number of doctors in Canada has increased slightly faster than the growth in the general population," said Scott.

"Has this improved access? Not really. One in seven Canadians still don't have a family doctor, a number that hasn't changed significantly over the last five years. That suggests to me that as patients and health care professionals, we need to change our thinking about who can provide the best care in the most appropriate setting."

"Why demand to see a specialist when your needs can be met by a general practitioner? Or a doctor, when you could speak with a nurse? Or see a nurse when really it's a dietitian who's in the best position to help you?" Roger Collier, CMAJ

DOI:10.1503/cmaj.109-3116 